\title{
Mental health status and risk factors for mental health problems in left-behind children of women migrant workers in Sri Lanka
}

\author{
B C V Senaratna ${ }^{1}$, H Perera ${ }^{2}$, P Fonseka ${ }^{1}$ \\ (Index words: migrant, children, mental health, education, Sri Lanka)
}

\begin{abstract}
Introduction Many married Sri Lankan women annually migrate for employment overseas. Despite widely speculated psychological consequences in these children, their mental health status has not been systematically studied using validated instruments.
\end{abstract}

Objectives To describe mental health status of children of women overseas workers and compare that with children of locally employed women, and to describe socio-demographic factors and risk factors associated with abnormal mental health in these children.

Methods A cross sectional comparative survey was conducted among 253 children (aged 5-10 years) of women migrant workers in the Colombo District and age and sex matched controls from same neighbourhood. Tools used were the validated Sinhala translation of Child Behaviour Check List (CBCL-S) and questionnaires on socio-demographic/risk factors and school functioning.

Results Mean CBCL-S scores and proportion of children with mental health problems were significantly higher in the study group. Not having an elder sibling, father not living with child, mother educated up to grade 5 or less, change of principal carer (PC) twice or more, living with a relative (or not living in own home), child not communicating freely with $\mathrm{PC}$, and not being permitted to engage in recreational activities at school were significantly associated with abnormal mental health of children of migrant women.

Conclusions A high awareness is required among health and social care authorities regarding mental health problems in these children and relevant risk factors in order to take preventive measures.

Ceylon Medical Journal 2011; 56: 153-158

\section{Introduction}

Labour export is Sri Lanka's second largest foreign exchange earner with over 250,000 persons migrating annually $[1,2]$. Total estimated labour migrants from Sri Lanka today stands at 1.8 million, of which $65 \%$ are women [1]. Nearly $80 \%$ of women migrants are married, of which $85 \%$ have children. Half of these children were aged 5 to 10 years at the time of mothers' migration [3] after which either father or a grandmother (less frequently a close family relative) becomes the main substitute carer for them [3]. This results in the child being moved from the family home or substitute carer/s moving in, thus altering family composition [4, 5].

\footnotetext{
${ }^{1}$ Department of Community Medicine, University of Sri Jayewardenepura and ${ }^{2}$ Department of Psychological Medicine, University of Colombo, Sri Lanka.
}

Correspondence: BCVS, e-mail: <chamaravs@yahoo.com>. Received 29 March and revised version accepted 8 July 2011. Competing interests: none declared. 
Many adverse outcomes for these children directly resulting from such disruption to family units have been reported. Incidence of abuse and neglect of children have been reported to be high $[3,4,6]$. Neglect is the commonest adversity faced by children with or without emotional and physical abuse, but incidents of sexual abuse by fathers or other male relatives are also reported [3]. In many cases, even non-abusive fathers fail to compensate for the absence of mother with amount of time spent with their children [3]. Further, school attendance of nearly $28 \%$ of such children is disrupted as they have to contribute to daily household chores or caring for younger siblings [3]. Although the effect on psychosocial health of these children have been studied [4, 6], no standardised and validated instruments have been used to measure mental health status.

The main objective of this study was to describe the mental health status of children of Sri Lankan women migrant workers and compare with that of children of women who are employed fulltime in Sri Lanka. Also, the socio-demographic risk factors associated with abnormal mental health in both groups were investigated.

\section{Methods}

This cross sectional study was conducted in the Colombo district, which has a population of 2,234,000 with $50.76 \%$ females, and is the highest annual contributor (12.87\%) to foreign employment in Sri Lanka [7-10].

Focus group discussions [FGDs] were conducted with primary-school teachers (as they were considered to be best informed about these children apart from families) to identify socio-demographic risk factors for mental health among children aged 5 to 10 years. Five FGDs, each including six to seven teachers from schools representing metropolitan, urban and semi-urban areas (from which the study sample was selected) were conducted. Contents of FGDs were tape recorded with their permission, transcribed immediately after each FGD, and were subjected to content analysis. These data were used to complete the Sociodemographic and Risk-factors Information Questionnaire [SDRIQ] mentioned below.

Assistance of local public health teams [PHTs] was used to identify children of women migrant workers (study group) and age and sex matched children of mothers in fulltime employment in Sri Lanka (control group). Children 5 to 10 years old and whose mothers have been working overseas for a minimum period of twelve months as unskilled workers or housemaids were included in the study [9]. Inclusion criteria for control group were that children matched in age and sex whose mothers were employed fulltime in Sri Lanka for a minimum period of twelve months in the same occupational category as migrant workers, and lived in the same neighbourhoods that were included in the control group. Children with evidence of a psychological disorder that pre-dated mother's migration/employment, a physical disability, or a chronic physical illness that required frequent medications during the last six months, were excluded from the study.
Calculated sample size was 224 matched pairs of children, which was built up to 253 to include all children identified through PHTs.

Validated Sinhala translation of Child Behaviour Check List (CBCL-S) and SDRIQ were interviewer administered to the principal carer [PC] of children [11].

Information related to school function (academic performance and attendance) was obtained from respective class teachers of children in both groups, using a self-administered questionnaire. Informed consent were obtained from all who were involved in the study. Ethical Review Committee of Faculty of Medical Sciences, University of Sri Jayewardenepura approved this study. Chi square test was performed to check differences in family and school data between study and control groups. Based on calculated individual total CBCL-S scores, each child was categorised as either abnormal or normal. Study and control groups were separately analysed using odds ratios to determine respective risk factors for mental health problems. To control for confounders, multivariate logistic regression was used.

\section{Results}

There were 136 matched pairs of boys (53.8\%) and 117 matched pairs of girls (46.2\%). Mean age was 8 years ( $\mathrm{SD}=1.7$ years, median 8 years, mode 10 years).

Table 1 shows relevant family data in which study and control groups showed statistically significant differences. Comparatively more children in the study group did not have any siblings, did not have their fathers living with them, had single mothers, lived in extended families and did not live in their own homes.

More students in the study group showed a lower rate of school attendance and were weak in studies [Table 2]. Percentage of 'good or very good'students was double in the control group compared to the study group.

When dichotomised based on the total CBCL-S scores significantly more children in the study group had abnormal scores (Table 3). The mean of the total CBCL-S scores of children in study group (17.5) was also significantly higher $(\mathrm{p}=0.02)$ than that of controls (15.4).

Not permitting children to engage in recreational activities at schools and in aesthetic and sports activities, low educational attainment of mother, living in a nuclear family and separation of parents posed high risks for abnormal scores in the study group (Table 4).

To adjust for possible confounding effect by other variables on the above-mentioned variables, forward conditional multivariate binary logistic regression was performed separately for two groups (Table 5). Children in study group who did not have elder siblings, whose fathers were not living with them, whose PC changed more than once, who were living in a relative's house, and who were not permitted to engage in recreational activities at school were at higher risk of abnormal CBCL scores. Although children with above characteristics in control group were also at high risk of abnormal CBCL scores, these were not 
statistically significant. However, less educated mothers were a significant risk factor for abnormal CBCL scores for both groups. Similarly, children in both groups who did not communicate freely with their PCs were at higher risk of having abnormal CBCL scores, and this risk was higher for study group than controls.

Table 1. Comparative family data of study and control groups

\begin{tabular}{|c|c|c|c|c|}
\hline Characteristic & Study group n (\%) & Control group n (\%) & $\chi^{2}$ & $p$ value \\
\hline \multicolumn{5}{|l|}{ Has siblings } \\
\hline Yes & $177(70.0)$ & $212(83.8)$ & 13.62 & $<0.001$ \\
\hline No & $76(30.0)$ & $41(16.2)$ & & \\
\hline \multicolumn{5}{|c|}{ Father living with child } \\
\hline Yes & $120(51.3)$ & $195(82.6)$ & 52.23 & $<0.001$ \\
\hline No & $114(48.7)$ & $41(17.4)$ & & \\
\hline \multicolumn{5}{|c|}{ Parents' marital status } \\
\hline Currently married & $172(68.0)$ & $210(83.0)$ & 22.77 & \\
\hline Separated & $60(23.7)$ & $23(9.1)$ & & $<0.001$ \\
\hline Divorced & 9(3.6) & $4(1.6)$ & & \\
\hline Widowed & $12(4.7)$ & $16(6.3)$ & & \\
\hline \multicolumn{5}{|l|}{ Family type } \\
\hline Nuclear & $73(28.9)$ & 144(56.9) & 40.67 & $<.001$ \\
\hline Extended & $183(71.1)$ & $109(43.1)$ & & \\
\hline \multicolumn{5}{|l|}{ Home type } \\
\hline Own home & $138(54.5)$ & $199(78.7)$ & 33.06 & $<.001$ \\
\hline Relative’s & $115(45.5)$ & $54(21.3)$ & & \\
\hline \multicolumn{5}{|c|}{ Number of persons in household } \\
\hline 5 or less & $125(49.4)$ & 164(64.8) & 12.27 & $<.001$ \\
\hline$>5$ & $128(50.6)$ & $89(35.2)$ & & \\
\hline
\end{tabular}

Table 2. Comparative school related data of study and control groups

\begin{tabular}{lcccc}
\hline Characteristic & Study group $\mathrm{n}(\%)$ & Control group $\mathrm{n}(\%)$ & $\chi^{2}$ & $p$ value \\
\hline $\begin{array}{l}\text { Percentage attendance in } \\
\text { schooling children }\end{array}$ & & & & \\
$0-20$ & $3(1.3)$ & $4(1.8)$ & 55.74 & $<.001$ \\
$21-40$ & $6(2.6)$ & $6(2.7)$ & & \\
$41-60$ & $24(10.3)$ & $5(2.2)$ & & \\
$61-80$ & $109(47.0)$ & $48(21.5)$ & & \\
$81-100$ & $90(38.8)$ & $160(71.7)$ & & \\
School performance & & & & \\
Very weak & $11(4.7)$ & $9(4.0)$ & $56.93^{\text {a }}$ & $<.001$ \\
Weak & $109(47.0)$ & $31(13.9)$ & & \\
Average & $82(35.3)$ & $125(56.1)$ & & \\
Good or very good & $30(13.0)$ & $58(26.0)$ & & \\
\hline
\end{tabular}

a ‘Very weak’ and 'Weak’ groups amalgamated; ‘Average’ and ‘Good or Very good’ groups amalgamated. 
Table 3. Abnormal and normal CBCL scores of the study and control groups

\begin{tabular}{lcccc}
\hline CBCL scores & Study group n (\%) & Control group n (\%) & $\chi^{2}$ & $p$ value \\
\hline Abnormal & $57(22.5)$ & $31(12.3)$ & 9.3 & 0.002 \\
Normal & $196(77.5)$ & $222(87.7)$ & & \\
Total & $253(100.0)$ & $253(100.0)$ & \\
& & & \\
\hline
\end{tabular}

Table 4. Variables associated with abnormal CBCL scores in the study group

\begin{tabular}{lcccc}
\hline Variable & \multicolumn{2}{c}{ Mental health status } & OR (CI) & $p$ value \\
& $\begin{array}{c}\text { Abnormal } \\
n(\%)\end{array}$ & $\begin{array}{c}\text { Normal } \\
n(\%)\end{array}$ & & \\
\hline No elder siblings & $49(86.0)$ & $61(31.1)$ & $13.6(6.0-30.4)$ & $<0.001$ \\
Father not living with child & $51(89.5)$ & $81(41.3)$ & $12.1(4.9-29.5)$ & $<0.001$ \\
Separated parents & $39(68.4)$ & $21(10.7)$ & $21.0(9.8-44.9)$ & $<0.001$ \\
Mother's level of education <grade 5 & $45(81.8)$ & $46(23.8)$ & $28.4(3.7-217.2)$ & 0.001 \\
PC changed twice & $31(57.4)$ & $40(21.2)$ & $6.6(3.3-13.1)$ & $<0.001$ \\
PC changed >twice & $6(11.1)$ & $4(2.1)$ & $12.8(3.3-49.9)$ & $<0.001$ \\
Nuclear family & $50(87.7)$ & $23(11.7)$ & $53.7(21.8-132.5)$ & $<0.001$ \\
Household size >5 & $27(47.4)$ & $59(30.1)$ & $9.1(2.1-38.6)$ & 0.003 \\
Frequently disturbed home environment & $5(8.8)$ & $5(2.6)$ & $5.0(1.4-18.6)$ & 0.02 \\
Frequently disturbed neighbourhood environment & $28(49.1)$ & $46(23.5)$ & $7.5(2.4-22.9)$ & $<0.001$ \\
Child does not communicate freely & $7(12.3)$ & $6(3.1)$ & $4.4(1.4-13.8)$ & 0.01 \\
Recreation not permitted & $41(74.5)$ & $41(22.2)$ & $10.3(5.1-20.7)$ & $<0.001$ \\
Sports not permitted & $8(57.1)$ & $6(4.2)$ & $30.7(8.0-116.7)$ & $<0.001$ \\
Aesthetic activities not permitted & $9(64.3)$ & $9(6.2)$ & $27.0(7.4-97.5)$ & $<0.001$ \\
Recreation activities at school not permitted & $8(57.1)$ & $2(1.4)$ & $94.6(16.4-545.7)$ & $<0.001$ \\
\hline & & & & \\
\hline
\end{tabular}


Table 5. Risk factors significantly associated with abnormal CBCL scores in study group and control group following multivariate logistic regression analysis

\begin{tabular}{|c|c|c|c|c|}
\hline \multirow[t]{2}{*}{ Characteristic } & \multicolumn{2}{|c|}{ Study group } & \multicolumn{2}{|c|}{ Control group } \\
\hline & OR $(95 \%$ CI $)$ & $p$ value & OR $(95 \%$ CI) & $p$ value \\
\hline $\begin{array}{l}\text { No elder siblings ( } c f \text { has } \\
\text { elder siblings) }\end{array}$ & $4.7(1.3-16.8)$ & 0.02 & b & \\
\hline $\begin{array}{l}\text { Father not living with child } \\
\text { (cfliving with child) }\end{array}$ & $11.5(2.5-53.4)$ & 0.002 & b & \\
\hline $\begin{array}{l}\text { Mother educated up to grade } 5 \\
\text { or less ( } c f \text { beyond grade } 5 \text { ) }\end{array}$ & $10.2(2.8-37.4)$ & $<0.001$ & $12.5(2.3-67.8)$ & 0.003 \\
\hline PCP changed more than once ( $c f$ once) & $10.5(2.7-40.5)$ & 0.001 & $\mathrm{~b}$ & \\
\hline Live in relative’s home ( $c$ f own home) & $4.8(1.3-17.4)$ & 0.02 & $\mathrm{~b}$ & \\
\hline $\begin{array}{l}\text { Child communicates freely ( } c f \text { does } \\
\text { not communicate freely) }\end{array}$ & $89.0(2.4-330.0)$ & 0.02 & $13.7(1.4-138.5)$ & 0.03 \\
\hline $\begin{array}{l}\text { Recreations at school not permitted } \\
\text { (cf permitted) }\end{array}$ & $15.2(3.7-62.4)$ & $<0.000$ & $\mathrm{~b}$ & \\
\hline
\end{tabular}

${ }^{\text {b}}$ Variable not in equation

\section{Discussion}

Previous studies on mental health of school-aged children of migrant workers in Sri Lanka, have neither used validated instruments nor quantitatively studied risk factors for mental health problems. A few have reported a variety of symptoms and an increased vulnerability to mental health problems in these children. For example 12\% of children of migrant workers were difficult to discipline, subjected to mental disturbances, and had disruptive behaviour [13,14].

Our study shows that the absence of the mother from the country as a singular factor caused a two fold increase in mental health problems of children. Similar findings have also been reported among pre-school children [15]. Prevalence of mental health problems in our study group was higher than that previously reported for Sri Lankan adolescents (19\%) and pre-schoolers (10\%) [16,17]. Similar studies from other Asian countries have been supportive or inconclusive regarding absence of mother as a significant aetiological factor in mental health problems in children [18].

A confiding relationship with primary carer is important for children and therefore it is understandable that children who did not communicate freely with their PCs had a higher CBCL score in our study [19]. Divorce or separation among migrant women in this study is higher than previous figures [3,15], compared to $12 \%$ reported by Athauda in 1994 [15] and 16\% by Ratnayake in 1999 [3]. This may reflect a changing trend in the society as a whole or in migrant women per se. Also, single motherhood itself could be a reason for migration. Other Asian studies also show that separation and divorce are high among migrant workers [18].

Extended families protect children due to enriched environment provided by grandparents and extended family help to cope with effects of mother's migration $[18,20]$. However, a large household size significantly increased the risk of mental disorders in children, the reason for which is unclear [21]. Educational achievement of parents, especially that of mothers, is an important correlate of mental health [22].

Most of the variables studied lost significance under multivariate analysis indicating the effect of confounders. However, certain factors independently increased risks to mental health of children in the study group but not in the control group.

A main limitation in our study was that FGDs were conducted only with teachers, which prevented access to information from relevant others. Also, the study was conducted exclusively in an urban and semi-urban setting. As such, caution should be exercised in applying these 
findings to other population settings, taking into account social and demographic differences.

In conclusion a high awareness is required among health and social care authorities regarding mental health problems in children of women migrant workers. Preventive measures should be introduced to minimise mental health problems among these children.

\section{Acknowledgements}

We thank Professor Kumudu Wijewardane and staff of International Maternal and Child Health, University of Uppsala for their guidance, and SIDA/SAREC for financial assistance.

\section{References}

1. Central Bank of Sri Lanka. Annual Report - 2008. 2009, Central Bank of Sri Lanka: Colombo.

2. Department of Census and Statistics. Comparison of male migrant workers, housemaids and other female migrant workers 1996-2008. Available at: http://www. statistics. gov.lk/NCMS/RepNTab/Tables/SLBFE/Tab3.pdf. 2010. Accessed 20.10.2010.

3. Ratnayake K. Female migration from Sri Lanka to Middle East: is the remedy worse than the disease? Sri Lanka Journal of Population Studies 1999; 2: 42-59.

4. Fernando V. The physical psychological and social impact on children. LOGOS 1989; 28: 1-56.

5. Senaratna BCV. Mental health status of the children of migrant workers in Colombo district. Postgraduate Institute of Medicine. 2007, University of Colombo: Colombo.

6. Dias M, Jayasundere R. Sri Lanka. The anxieties and opportunities of out-migration, in Migrant workers and human rights - out migration from South Asia. In: Ahn P-S ed. 2004, International Labour Organisation. 153-182.

7. Department of Census and Statistics. Statistical Tables. 2007. Available from: http://www.statistics.gov.lk/ census2001/population/text_tabb.htm. accessed on 16.3.2007.

8. Department of Census and Statistics. Statistical Tables. Department of Census and Statistics - Sri Lanka. Available at: http://www.statistics.gov.lk/population/tables.pdf. 2007. Accessed 16.3. 2007.

9. Sri Lanka Bureau of Foreign Employment. Statistical handbook on migration 2003. Colombo: Research Division of Sri Lanka Bureau of Foreign Employment. 2004.
10. Sri Lanka Bureau of Foreign Employment. Annual statistical report of foreign employment - 2005. (Online) Sri Lanka Bureau of Foreign Employment. Available at: http:// www.slbfe.lk/feb/statistics/stat7.pdf 2006. Accessed 18.3.2007.

11. Senaratna BCV, Perera H, Fonseka P. Sinhala translation of child behaviour checklist: validity and reliability. Ceylon Medical Journal 2008; 53: 40-4.

12. Central Bank of Sri Lanka. Key socio economic indicators for Sri Lanka 1953 - 2003/04. Available at: http:// www.cbsl.gov.lk/pics_n_docs/10_publication/_docs/cfs/ cfs_ksei1953-04p1.html. 2007. Accessed 20.5.2007.

13. Karunasekera KAW, Kuruppuarachchi KALA, Gunasekera DPS. Psychological impact on children and families of Middle East workers. Annual Scientific Sessions of the Sri Lanka College of Paediatricians, Sri Lanka. Sri Lanka College of Paediatricians 2000.

14. Perera M. A profile of female migrants (analysis of data from an AAFLI survey in Polgahawela and estate sector in Deraniyagala). Marga Institute, Colombo, 1997.

15. Athauda GATK. Influence of employment status of the mother on the physical growth, development and behaviour of pre-school children. Postgraduate Institute of Medicine. 1994, University of Colombo, Colombo.

16. Perera $\mathrm{H}$. Mental Health of adolescent school children in Sri Lanka - a national survey. Sri Lanka Journal of Child Health 2004; 33: 78-81.

17. Perera H, Gunatunge C. Screening for mental health problems in urban preschool children - a pilot study. Sri Lanka Journal of Child Health 2004; 33: 39-42.

18. Bryant J. Children of international migrants in Indonesia, Thailand, and the Philippines: a review of evidence and policies. UNICEF Innocenti Research Centre: Florence 2005.

19. Blower A, Addo A, Hodgson J, Lamington L, Towlson K. Mental health of 'looked after' children: a needs assessment. Clinical Child Psychology and Psychiatry 2004; 9: 117-29.

20. Jendrek MP. Grandparents who parent their grandchildren: effects on lifestyle. Journal of Marriage and the Family 1993; 55: 609-21.

21. Reinherz HZ, Paradis AD, Giaconia RM, Stashwick CK, Fitzmaurice G. Childhood and adolescent predictors of major depression in the transition to adulthood. American Journal of Psychiatry 2003; 160: 2141-7.

22. McCulloch A, Wiggins RD, Joshi HE, Sachdevet D. Internalising and externalising children's behaviour problems in Britain and the US: relationships to family resources. Children and Society 2000; 14: 368-83. 